\title{
Studies on the Innovation of College "Business-Study Integration” Talent Training Mode
}

\author{
Xuan Wang \\ Wuhan Huaxia University of Technology, Wuhan Hubei, 430223, China
}

Keywords: College education, Business-study integration, Talent training mode, Innovation

\begin{abstract}
College "business-study integration” talent training mode aims at practicing students' skill, applying theoretical knowledge into specific practice, and making contribution to enterprise development while improving professional skills. This paper will explore college "business-study integration” talent training mode by combining basic contents, clarify specific practice process, and demonstrate the application value of this talent training mode through practice.
\end{abstract}

\section{Introduction}

It is critical to achieve the training mode of combining vocational school with apprentice. Business-study integration is a new way and new method which is formed gradually through running school jointly by school and enterprise. The essence of it is industry-study cooperation and joint education by combining school resource and social educational resource, students' theoretical study and practice thoroughly, and carrying out "business-study integration and self-innovation" during the process of school-enterprise cooperation and constant practical process. During the constant process, students can improve their self-employed awareness to improve practical operational ability in basic practice, and improve their professional moral accomplishment for cultivating their learning motive, reducing adaptation time to employment, and providing better service for industry, carrying out school-running mission, and making contribution to social development.

\section{Overview of college "business-study integrated" talent training mode}

\subsection{Incubation under entrepreneurship condition}

Business school has set e-business major which is to implement client service, product shooting, product image processing and network marketing into detailed practice through "business-study integration and self-innovation” teaching mode and school-enterprise” joint running by establishing real stores in school and establishing classroom in virtual network stores, and to introduce enterprise real working environment and working projects into school so as to carry out "two responsibilities for one product" for the purpose of internship in teaching and productivity operation responsibility[2]. Business school, e-business major and multiple companies cooperate to establish high-standard and modern e-business training base. Schools provide site, student resource and teacher resource. Enterprises provide network marketing training instructors and funds required for purchasing. Under such precondition, sign a three-year cooperation agreement, and construct e-business network marketing internship training base as schedule and put into use. Until now, product purchasing, uploading, store decoration, signing with express company, online marketing, and after-sale service can help students improve their internship activity and learning interest. In such environment, students can truly understand the close connection between their major and position skill required by enterprises. They can create benefits for enterprise and meanwhile students and teachers' practical abilities have been improved. 


\subsection{Practical training in entrepreneurial practice}

Under the condition of school-enterprise cooperation, both can establish network training base and establish talent training and communication system between e-business major, school and enterprise. Schools can cultivate enterprise employees and professional teachers have the chance to practice in enterprises and learn enterprise production skill according to position requirements. This is good for school teaching work and good for enterprises to provide real startup environment for students. Meanwhile, it is good for enterprise customer service. Teachers can practice in enterprises and do part-time job in promotion so as to create benefits for school, and get enterprise technical experts to participate in school course reform and innovation.

\subsection{Mainly serve social development}

Medium small and micro-sized enterprises have a lot of technical problems such as technical service, consultancy service, training service problems, to establish "one-stop” service providing mode. Several e-business medium small and micro-sized enterprises sign cooperation agreement with e-business. School teachers and students provide product network recommendation, online selling so as to save sale cost and improve enterprise sales volume. Meanwhile, enterprise can provide internship position for students. By doing so, students can convert theory into practice, and they can intensify and solidify their practice.

\section{Specific practice of college "business-study integrated" talent training mode}

Colleges with long history of school ruing and occupational education training can cooperate with local enterprises and refer to relevant school-business cooperation experience. According to the actual condition, the college can conduct working-learning alternation and school-enterprise cooperation work. This has essentially changed the traditional course and school centered teaching mode, and gradually transferred skill-oriented talent cultivation mode to working-learning alternation and school-enterprise mode, and finally established a "business-study integration and self-innovation" teaching mode. The implementation of business-study integration should be started by formulating training steps for enterprise-school cooperation, and carrying out talent cultivation implementation procedure in the whole process of education, which is the best guarantee for working-learning integration. According to the target of e-business professional talent cultivation and regional economic characteristics, cooperate with enterprise in professional guidance, and conduct "business-study integration and self-innovation" teaching mode so as to help students to develop self-employed behavior habit.

\subsection{Confirm cooperative enterprise required and sign cooperation agreement}

E-business major focuses on school-enterprise cooperation. The business school has carefully analyzed and verified relevant enterprises' talent demand after inspecting more than twenty e-business companies about their product market prospect, companyhardware condition, and social credit, and then carried out detailed investigation. At last, confirmed the unit to achieve "business-study integration and self-innovation" target, and properly singed "school-enterprise cooperative agreement" and "order type training agreement" so as to guarantee that school and enterprises can carry out activities regularly and effectively to lay foundation for successful practice.

\subsection{Establish professional steering committee for guiding teaching and startup}

"Professional steering committee" established jointly by school and enterprise can be the leader of students' entrepreneurship which contains teachers, enterprise experts, enterprise technical backbone members, etc. It will formulate talent cultivation plan each year regularly to discuss student training and internship issues. Meanwhile, while formulating "talent cultivation scheme, school-enterprise cooperative mechanism, and its implementation”, it requires to clarify each party’s responsibilities including school as the subject to provide site and equipment, students position provided by 
enterprise, and some theoretical course study completed at school so as to obtain standard daily management, provide necessary technical support and carry out reasonable communication meeting.

\section{3 "Business-study integration” constructs integrated teaching mode}

In current stage, the government advocates colleges to actively use "business-study integration and self-innovation" teaching mode, adheres to achieve reasonable tendency based on cultivating students' self-innovative ability. Faced up to the skill requirements and position standard required by the society, it has proposed the basic direction of "business-study integration", and mainly focused on relevant industry development trend, extracted relevant data information about corporate concept, culture and operation properly so as to guarantee both to formulate teaching mode suitable for enterprise development standard based on actual situation to achieve business-study integration teaching objective.

\subsection{Combine relevant technical experts to guide students' entrepreneurship}

During the development over the past two years, "business-study integration” teaching mode has received great attention. Under its influence, students started up business in school actively. Some colleges advocate to lead students to open online stores under the guidance of experts and technical backbone. "Business-study integration" is a new tendency. Students open up online stores not for profitable purpose but for trial of self-employment. Based on market positioning and website analysis, students can experience the hardship and achievements of startup through operation mode, website promotion and logistic system so as to own valuable entrepreneurship fortune and long-term practice target. Through promoting the basic concept of "business-study integration", students can obtain the chance of starting up business. They can adhere to basic entrepreneurship concept, break the misunderstanding from the society, build their entrepreneurship confidence, and give full play to their own potential.

\section{Practical effect of college "business-study integrated" talent training mode}

\subsection{Promote a clear college course system}

In college education, the basic education target is to cultivate batches of social application talents, which requires to continuously perfect college education course system so as to give full play of education value. Course system optimization design is further development of discipline system course used for vocational education for years. In traditional course system development, it mainly focuses on imparting basic knowledge. But the teaching system based on its interior logic structure correlation and cognition rule has highlighted teachers' dominant position. Reasonable implementation of "business-study integration" teaching mode can highlight students' dominant position, and help students to learn courses progressively so as to cater for relevant enterprise development requirements.

\section{2 “Business-study integration” has conducted industry standard project teaching}

In college education, course teaching should carry forward "task driven project oriented” guiding function, strictly implement social analysis work, and carry out design based on industry position work analysis, teaching analysis and different stages to construct a reasonable integrated teaching mode. Adhere to the cultivation key points in professional field and actual condition so that students can truly become talents making contribution for social development. The implementation of "business-study integration" teaching mode has strictly carried forward project system teaching and insist the index of user satisfaction.

\section{3 "Business-study integration” promotes win-win school-enterprise cooperation}

The "business-study integration" teaching mode has promoted win-win in school-enterprise cooperation and provided broader practice space through constructing reasonable training base. Schools have fully used scientific power and advantageous resources to provide continuous talent 
support. Enterprise have perfected talent training mechanism with rich practical experience, and guarantee to lay foundation for students' employment and development. Schools and enterprises combine teaching and scientific research resources so as to implement win-win mechanism. By doing so, the enterprise can show basic direction of "business-study integration" while achieving stable development.

\section{4 “Business-study integration” promotes students' entrepreneurship ability}

For college students, it is critical to master solid skills so as to obtain resources for future employment. The establishment of new type "business-study integration" teaching mode can help students own basic entrepreneurship awareness and practice their mobility in basic practice. Enterprise technical and teachers' guidance can help students fully know the basic procedures of opening online stores, and encourage them to solidify their skills. In addition, some students with independent operation ability can put theory into practice under the motivation of self-employed awareness. Students' self-employment can relieve the pressure of social employment competition. Also, some enterprises can find more capable talents, which has provided reliable basis for colleges to cultivate skill-oriented talents.

\section{Conclusions}

College "business-study integration" teaching mode has obtained some practical effect. But it is undeniable that in its exploration and perfection period, it requires colleges' attention to reasonable application so as to give full play of its value. During the process of penetrating to students' practical awareness, "business-study integration" teaching mode can help students to put into real actions so as to make contribution for enterprise development, become the skill-oriented talents required by the society and achieve win-win school-enterprise cooperation and sustainable development.

\section{Acknowledgements}

This research was financially supported by Hubei Provincial Education Science Planning Project "Studies on private college "business-study integration" talent training mode from organizational behavior perspective” (Grant NO. 2017GB140).

\section{References}

[1] Wang Yong. "Week, month, quarter and year" multi-layer working-learning integrated talent training mode and reflection-take CNC technology application specialty in Lanzhou Polytechnic Secondary School and other professional schools as the example, Journal of Northwestern Adult Education College, 2016(05):111-113.

[2] Noisy-Parallel and Comparable Corpora Methodology for the Extraction of Bi-Lingual Equivalent Data at Sentence Level. Work. Computer Science. 2015.

[3] Proof over promise: towards a more inclusive ranking of Dutch academics in Economics \& Business, Anne-Wil Harzing, Wilfred Mijnhardt. Scientometrics. 2015 (1).

[4] Kang Jingqing. Studies on higher college talent training teaching-learning integration mode-from the perspective of students' participation in teaching management, Education and Teaching Forum, 2015(02):176-179.

[5] Environmental and ecological economics in the 21st century: An age adjusted citation analysis of the influential articles, journals, authors and institutions, Andreas G.F. Hoepner, Benjamin Kant, Bert Scholtens, Pei-Shan Yu. Ecological Economics. 2012.

[6] Zhao Jingyu. Studies of higher vocational school software technology specialty "industry-study integration" talent training mode application, Computer CD Software and Application, 2013,16(01):272-273. 